\title{
Epigenetic DNA-methylation regulation of genes coding for lipid raft-associated components: A role for raft proteins in cell transformation and cancer progression (Review)
}

\author{
SAMIR K. PATRA ${ }^{1,3}$ and SAVERIO BETTUZZI ${ }^{1,2}$ \\ ${ }^{1}$ Department of Medicina Sperimentale, University of Parma, via Volturno 39, I-43100 Parma; \\ ${ }^{2}$ Istituto Nazionale Biostrutture e Biosistemi (INBB), Rome, Italy
}

Received January 23, 2007; Accepted February 27, 2007

\begin{abstract}
Metastatic progression is the cause of most cancer deaths. Host tumour cell separation (fission) is accompanied by simultaneous acquisition of migrating capability of cancer cells, remodeling of cellular architecture and effective 'homing' in body host environment. Cell remodeling involves cytoskeletal protein-protein and lipid-protein interaction together with altered signaling. Alteration of signaling in tumour cells may affect expression of many genes also by DNAmethylation/demethylation. This would alter the steady-state intracellular level of structural proteins or metabolic enzymes, and notably enzymes involved in the biosynthesis of lipids, affecting the composition of membranes. Lipid rafts are small, heterogeneous, highly dynamic, sterol- and sphingolipidenriched domains that compartmentalize cellular processes. Small rafts can be stabilized to form larger platforms through protein-protein and protein-lipid interactions. Lipid rafts play an important role in intracellular protein transport, membrane fusion and trans-cytosis, also being platforms for cell surface antigens and adhesion molecules which are crucial for cell activation, polarization and signaling. Detachment of individual tumour cells from the host tumour lump requires lipid-protein-lipid raft (LPLR) reordering. Lipid rafts are also
\end{abstract}

Correspondence to: Professor Saverio Bettuzzi, Department of Medicina Sperimentale, University of Parma, via Volturno 39, I-43100 Parma, Italy

E-mail: saverio.bettuzzi@unipr.it

${ }^{3}$ Present address: Dr Samir Kumar Patra, Cancer Epigenetics Research, Kalyani (B-7/183), Nadia, West Bengal 741235, India

E-mail: skpatra_99@yahoo.com

Abbreviations: lipid-protein-lipid rafts, LPLRs; extracellular matrix, ECM; sterol regulatory element binding proteins, SREBPs; glycosyl phosphatidyl inositol, GPI; endoplasmic reticulum, ER; urokinase type plasminogen activator, uPA; matrix metalloproteinases, MMPs; vascular endothelial growth factor, VEGF; androgen receptor, AR; steroid receptors, SRs; endocytic recycling compartment, ERC; extracellular membrane vesicles from tumour cells, EMVTCs

Key words: epigenetics, DNA-methylation, lipid rafts, cancer metastasis, E-cadherin, caveolin-1, CD44, sphingomyelin, cholesterol, matrix metalloproteinase, growth factors, G-proteins, sterol regulatory element, CpG-islands involved in angiogenesis and local invasion, which occurs within the host tumour vicinity by exchange of enzymes, cytokines and motility factors that modify the surrounding extracellular matrix (ECM). Many cell surface adhesion, ECM, and signaling proteins (such as E-cadherin, catenin, CD44, MMP-9 and caveolin-1) are known to be absent or reduced following gene promoter-CpG-island hypermethylation in mid-stage growing tumours, but re-expressed (by gene promoter- ${ }^{\mathrm{m}} \mathrm{CpG}-\mathrm{DNA}$ demethylation) in carcinomas such as metastasized lung, prostate and sarcomas. The recent research acquisitions on lipid rafts have tremendous implications in understanding the genetic and biochemical bases of metastatic diffusion of cancer.

\section{Contents}

\section{Introduction}

2. Too many partners for lipid rafts

3. Lipid rafts and their role in membrane function and intracellular transport

4. Epigenetic mechanisms and cancer

5. Dynamic flux of methyl layer at the 5'-carbon of cytosine on promoter-CpG-islands of DNA regulates gene function

6. Some raft component genes harbour sterol regulatory elements and -CpG-islands

7. Lipid rafts in immune escape and in new blood vessel formation (neo-angiogenesis)

8. Lipid rafts in cell-surface architecture, cell-polarization and chemotaxis

9. Role of rafts in acquisition of metastatic potential

10. Conclusion and perspectives

\section{Introduction}

Epigenetic factors and molecular stress imposed by surrounding cell environment may cause imbalance of the intricate cell metabolic network and alter cell cycle regulation, ultimately participating to tumour growth and resistance to apoptosis, whereas a correct regulation of such events maintains health $(1,2)$. Lipid rafts (hereafter, rafts) are specialized supramolecular aggregates of sphingolipids (predominantly, sphingomyelin), cholesterol and gangliosides orchestrated by proteins with or without glycosyl-phosphatidyl-inositol (GPI)- 
Table I. Components of lipid rafts and raft-associated proteins: function and epigenetic regulation mechanism.

\begin{tabular}{|c|c|c|c|}
\hline Components & $\begin{array}{l}\text { Function/(significant difference in cancer: } \\
\text { up, } \uparrow ; \text { down, } \downarrow \text {; or cancer stage specific }, \uparrow \downarrow)\end{array}$ & Mechanism of control/regulation & Refs. \\
\hline \multicolumn{4}{|l|}{ Lipids } \\
\hline Cholesterol (Chol) & $\begin{array}{l}\text { Spacer between the hydrocarbon chains, } \\
\text { H-bonding with surface water and } \\
\text { sphingomyelin/(Yes } \uparrow)\end{array}$ & $\begin{array}{l}\text { Biosynthesis, transportation by } \\
\text { LDL, HDL, endocytic recycling }\end{array}$ & $\begin{array}{l}3,5-15,17,21,23 \\
24,42-48\end{array}$ \\
\hline Sphingomyelin (SM) & $\begin{array}{l}\text { Bilayer structure, macrodomain formation/ } \\
\text { (Yes } \uparrow \text { ) }\end{array}$ & $\begin{array}{l}\text { Biosynthesis and endocytic } \\
\text { recycling }\end{array}$ & $\begin{array}{l}3,5-15,17,19,23 \\
24,46,113\end{array}$ \\
\hline $\begin{array}{l}\text { Glycosphingolipids } \\
\text { (e.g., GM1) }\end{array}$ & $\begin{array}{l}\text { Various signaling and immuno-protection/ } \\
\text { (Yes } \uparrow \text { ) }\end{array}$ & $\begin{array}{l}\text { Biosynthesis and endocytic } \\
\text { recycling }\end{array}$ & $3,15,18,88$ \\
\hline $\begin{array}{l}\text { Lysophosphatidic } \\
\text { acid (LPA) }\end{array}$ & Signal-transduction/(Yes $\uparrow)$ & Biosynthesis & $3,17,68$ \\
\hline $\mathrm{PIP}_{2}$ & Signal transduction/(Yes $\uparrow)$ & Biosynthesis & $3,24,68$ \\
\hline \multicolumn{4}{|l|}{ Proteins } \\
\hline \multicolumn{4}{|l|}{ Integral/structural } \\
\hline $\begin{array}{l}\text { Caveolins } \\
(\text { Cav-1, -2, -3) }\end{array}$ & $\begin{array}{l}\text { Structural integrity of caveolae, signaling } \\
\text { through cytoskeleton, transport of } \\
\text { cholesterol to caveolae/(Yes } \uparrow \downarrow)\end{array}$ & $\begin{array}{l}\text { DNA-methylation, transcriptional, } \\
\text { translational, degradation, recycling } \\
\text { through caveolae }\end{array}$ & $\begin{array}{l}31,49,50,56,80 \\
108\end{array}$ \\
\hline $\mathrm{CD} 44$ & $\begin{array}{l}\text { Structural integrity, cell-cell contact, } \\
\text { membrane-cytoskeleton, signaling/(Yes } \uparrow \downarrow)\end{array}$ & $\begin{array}{l}\text { DNA-methylation, transcriptional, } \\
\text { translational, degradation }\end{array}$ & $\begin{array}{l}24,49,51-53,55 \\
80,83,84,98 \\
99-101\end{array}$ \\
\hline E-cadherin & $\begin{array}{l}\text { Structural integrity, cell-cell contact, } \\
\text { membrane-cytoskeleton: Cadh-catenin- } \\
\text { actin/(Yes } \uparrow \downarrow)\end{array}$ & $\begin{array}{l}\text { DNA-methylation, transcriptional, } \\
\text { translational, proteolytic } \\
\text { degradation }\end{array}$ & $\begin{array}{l}80,82,101-107 \\
110,117\end{array}$ \\
\hline Integrins & $\begin{array}{l}\text { Signaling, chemotaxis and polarization and } \\
\text { motility/(Yes } \uparrow \downarrow)\end{array}$ & $\begin{array}{l}\text { Transcriptional, translational, } \\
\text { degradation, endocytic recycling }\end{array}$ & $49,67,71,89$ \\
\hline $\begin{array}{l}\text { Flotilins (FLO-1 } \\
\text { and } 2 \text {; aka, reggies } \\
\text { or cavatellins) }\end{array}$ & $\begin{array}{l}\text { Structural integrity, cell-cell contact, } \\
\text { membrane-trafficking/(Yes } \uparrow \downarrow)\end{array}$ & $\begin{array}{l}\text { Transcriptional, translational, } \\
\text { degradation, endocytic recycling }\end{array}$ & $\begin{array}{l}7,24,80 \text { and refs. } \\
\text { therein }\end{array}$ \\
\hline $\mathrm{LAT} / \mathrm{PAG}$ & Linker for activation of $\mathrm{T}$ cell, signaling & $\begin{array}{l}\text { Transcriptional, translational, } \\
\text { degradation, endocytic recycling }\end{array}$ & $\begin{array}{l}7 \text { and refs. } \\
\text { therein }\end{array}$ \\
\hline MAL/BENE & $\begin{array}{l}\text { Transport, endocytosis, interaction with } \\
\text { caveolin, signaling }\end{array}$ & $\begin{array}{l}\text { Transcriptional, translational, } \\
\text { degradation, endocytic recycling }\end{array}$ & $7,49,80,124$ \\
\hline Stomatins VIP36 & $\begin{array}{l}\text { Transport, endocytosis, interaction with } \\
\text { caveolin, signaling }\end{array}$ & $\begin{array}{l}\text { Transcriptional, translational, } \\
\text { degradation, endocytic recycling }\end{array}$ & $7,49,80$ \\
\hline \multicolumn{4}{|l|}{ Acylated exoplasmic } \\
\hline $\begin{array}{l}\text { GPI-linked } \\
\text { proteins }\end{array}$ & $\begin{array}{l}\text { Protection against immune attack, signaling/ } \\
\text { (Yes } \uparrow \downarrow)\end{array}$ & $\begin{array}{l}\text { Enzymatic modifications of the } \\
\text { respective proteins }\end{array}$ & $\begin{array}{l}3,4 \text { and refs. } \\
\text { therein, } 25,49,80\end{array}$ \\
\hline Thy-1 & Thymocyte development, signaling & $\begin{array}{l}\text { Transcriptional, translational, } \\
\text { degradation }\end{array}$ & $49,80,88$ \\
\hline $\begin{array}{l}\text { Alkaline } \\
\text { phosphatase }\end{array}$ & Signaling, protein dephosphorylation & $\begin{array}{l}\text { Transcriptional, translational, } \\
\text { degradation }\end{array}$ & $20,24,49,80$ \\
\hline Folate receptor & $\begin{array}{l}\text { Accumulating folic acid, important in } \\
\text { various metabolic pathways }\end{array}$ & $\begin{array}{l}\text { Transcriptional, translational, } \\
\text { degradation, endocytic recycling }\end{array}$ & $4,21,24$ \\
\hline \multicolumn{4}{|l|}{ Acylated cytoplasmic } \\
\hline $\begin{array}{l}\text { Src-family tyrosine } \\
\text { kinases (NRTKs) }\end{array}$ & Protein phosphorylation, signaling & $\begin{array}{l}\text { Transcriptional, translational, } \\
\text { degradation }\end{array}$ & $\begin{array}{l}6,24,49,74,80 \\
117,118\end{array}$ \\
\hline G-proteins & Energy-dependent signaling/(Yes $\uparrow)$ & $\begin{array}{l}\text { Transcriptional, translational, } \\
\text { degradation }\end{array}$ & $\begin{array}{l}6,49,85-89,114 \\
120\end{array}$ \\
\hline eNOS & Signaling, erectile function/(Yes $\uparrow \downarrow)$ & $\begin{array}{l}\text { Transcriptional, translational, } \\
\text { degradation }\end{array}$ & $6,49,108$ \\
\hline
\end{tabular}


Table I. Continued.

\begin{tabular}{|c|c|c|c|}
\hline Components & $\begin{array}{l}\text { Function/(significant difference in cancer: } \\
\text { up }, \uparrow ; \text { down, } \downarrow ; \text { or cancer stage specific }, \uparrow \downarrow)\end{array}$ & Mechanism of control/regulation & Refs. \\
\hline H-Ras & Energy-dependent signaling & $\begin{array}{l}\text { Transcriptional, translational, } \\
\text { degradation }\end{array}$ & $6,49,74,77,119,122$ \\
\hline uPA & $\begin{array}{l}\text { ECM-substrate degradation and activation, } \\
\text { metastasis/(Yes } \uparrow \downarrow)\end{array}$ & $\begin{array}{l}\text { DNA-methylation, transcriptional, } \\
\text { translational, degradation }\end{array}$ & $66,89,92$ \\
\hline uPAR & $\begin{array}{l}\text { Harbour uPA and transmission of signals/ } \\
\text { (Yes } \uparrow \downarrow \text { ) }\end{array}$ & $\begin{array}{l}\text { DNA-methylation, transcriptional, } \\
\text { translational, degradation }\end{array}$ & 89,93 \\
\hline \multicolumn{4}{|l|}{ Scavenger receptors } \\
\hline CD36 & Fatty acid transport, angiogenesis, signaling & $\begin{array}{l}\text { Transcriptional, translational, } \\
\text { degradation }\end{array}$ & $3,7,49$ \\
\hline SRBI & $\begin{array}{l}\text { Lipoprotein assembly, scavenging free } \\
\text { radicals }\end{array}$ & $\begin{array}{l}\text { Transcriptional, translational, } \\
\text { degradation }\end{array}$ & $3,7,49$ \\
\hline RAGE & Ig-protein transport and signaling & $\begin{array}{l}\text { Transcriptional, translational, } \\
\text { degradation }\end{array}$ & $3,6,7,49$ \\
\hline EGFR & Harbour EGF, signaling/(Yes $\uparrow \downarrow)$ & $\begin{array}{l}\text { DNA-methylation, transcriptional, } \\
\text { translational, degradation }\end{array}$ & $3,6,7,49$ \\
\hline VEGFR etc. & Harbour VEGF, and signaling/(Yes $\uparrow \downarrow)$ & $\begin{array}{l}\text { DNA-methylation, transcriptional, } \\
\text { translational, degradation }\end{array}$ & 76 \\
\hline $\mathrm{AMF} / \mathrm{PHI}$ & $\begin{array}{l}\text { Hexose-phosphate isomerisation, cell } \\
\text { motility }\end{array}$ & $\begin{array}{l}\text { DNA-methylation, transcriptional, } \\
\text { translational, degradation }\end{array}$ & 71,89 \\
\hline $\begin{array}{l}\text { Chol-biosynthesis } \\
\text { gene }\end{array}$ & Cholesterol metabolism/(Yes $\uparrow \downarrow)$ & $\begin{array}{l}\text { Transcriptional, translational, } \\
\text { degradation }\end{array}$ & $5,9,10,47,48$, Abs. $^{a}$ \\
\hline $\begin{array}{l}\text { SM-biosynthesis } \\
\text { gene }\end{array}$ & Sphingomyelin metabolism/(Yes $\uparrow \downarrow)$ & $\begin{array}{l}\text { Transcriptional, translational, } \\
\text { degradation }\end{array}$ & Abs. ${ }^{a}$ \\
\hline ACAT-1, -2 & Esterification of cholesterol & $\begin{array}{l}\text { Transcriptional, translational, } \\
\text { degradation }\end{array}$ & 5,28 \\
\hline MMP-3, -9 & $\begin{array}{l}\text { Degradation of collagens of extracellular } \\
\text { matrix/(Yes } \uparrow \downarrow)\end{array}$ & $\begin{array}{l}\text { DNA-methylation, transcriptional, } \\
\text { translational, degradation }\end{array}$ & $67,71,78,89,90,94$ \\
\hline
\end{tabular}

${ }^{\mathrm{a}} \mathrm{Qu} \mathrm{J}-\mathrm{N}$, et al, Proc Am Assoc Cancer Res 44: abs. 209, 2003.

anchorage (3-5). In recent years researchers have discovered that rafts, besides being important structural components for delivery of lipids and proteins in the body, play important and active roles in membranes fusion, signal transduction and transcytosis (3-10). It has long been known that cancer cells produce more cholesterol and sphingolipids than the normal cell counterparts (11-17). Some cancer cells, and particularly those which show the most aggressive phenotype, shed plasma membranes with cholesterol, sphingomyelin and gangliosides. This would allow these aggressive cells to counteract host immune response and escape destruction by the immune system $(18,19)$. Furthermore, cells depleted with cholesterol by exogenous agents (drug treatment, pathogens, carcinogens etc.) have been found to disrupt rafts $(3,9,10)$. Here, the epigenetic events associated with biogenesis and molecular orchestration of lipid raft components and their possible role in tumourigenesis will be discussed. The purpose of this review is to highlight raft involvement in tumour growth, angiogenesis, immune escape and metastatic progression of cancer in the general view of their modulation by epigenetic reprogramming (on/off) of the genes coding for raft-associated proteins through sterol regulatory element binding protein (SREBP)-transcription factors. In addition, the role of dynamic flux of methyl layers on DNA at the cytosine- ${ }^{5} \mathrm{C}$ position of promoter-CpG-islands (hereafter, DNA-methylation) will also be discussed to see whether DNA-methylation of certain raft-component genes is responsible for tumour growth and may allow tumour cells to metastasize.

\section{Too many partners for lipid rafts}

Interaction of DNA with liposomes (containing synthetic cationic lipids) is well known and gene delivery for gene therapy has been attempted in many different fields on the basis of this knowledge. RNA, at least mRNA, operate in a lipid-membrane environment for protein synthesis; the endoplasmic reticulum (ER). Nevertheless, main components of dynamic assembling of rafts are cholesterol, sphingolipids and 
proteins, while the presence of nucleic acids is to be excluded to date. These protein and lipid components of rafts have essential functions partially responsible for providing the duplicating cell with the high processivity required to reorganize cellular architecture of the offspring cells through cytokinesis. In the membrane structure, cholesterol is believed to serve as a spacer between the hydrocarbon chains of the sphingolipids, and to function as a dynamic glue that keeps the raft assembly together, having higher affinity to raft sphingolipids than to unsaturated phospholipids. Removal of cholesterol leads to dissociation of most proteins from rafts and renders them non-functional (3-10). The existence of rafts was first inferred from the differential trafficking of lipids and lipid-anchored proteins (PLAP-alkaline phosphatase, and HGinfluenza virus hemagglutinin) to the apical macro-domain of polarized epithelial cells $(3,5,20)$, and later experimentally identified by determining with membrane-protein insolubility in cold non-ionic detergent, Triton X-100 (15,20-23). Thus, detection of complex formation with detergent resistant membranes (DRMs) became a useful approach to test whether or not a protein associates with rafts. After dissolving membranes or cells with Triton X-100, Lubrol or CHAPS at $4^{\circ} \mathrm{C}$, raftassociated lipids and proteins remain insoluble, floating to low density by sucrose gradient centrifugation. Biophysical studies have revealed that lipid exists in several phases in the lipid bilayer model, including gel, liquid-ordered and liquiddisordered states, in order of increasing fluidity. In the gel state, lipids are semi-frozen, whereas at the opposite extreme, the liquid-disordered state, the whole lipid bilayer is fluid as proposed by the Singer-Nicholson model $(3-10,21,23)$. Rafts are first assembled in the Golgi complex in mammalian cells $(5,9,10)$. Cholesterol is synthesized in the ER, as well as ceramide, the hydrophobic backbone of sphingolipids. However, most of the sphingolipid polar-head groups are attached to ceramide in the Golgi complex, where raft assembly takes place $(3,5,10,20)$. Table I summarizes the components of rafts as identified by detergent insolubility and sucrose gradient centrifugation, immuno-colocalization, and other biophysical methods such as fluorescence resonance energy transfer (FRET) and quantitative high resolution MS spectrometry. The presence of each component cited in Table I in rafts is supported by the experimental work of at least two laboratories, and further confirmed by unbiased proteomics of lipid rafts (24). This approach yielded a total of 703 proteins, which were identified in detergent-resistant fractions, while 585 were detected in $\mathrm{pH}$ carbonate-resistant fractions. Of the 703 detergent-resistant proteins, 392 were quantified and 241 were validated as authentic raft proteins. Identification of such a large set of true raft proteins begs the question of how specific is the assembling of rafts, and what is the connection between raft and signaling (24). In fact, lipid rafts are often linked to signal transduction pathways, in particular as coordinators of the initial events in the cascades (6).

\section{Lipid rafts and their role in membrane function and intracellular transport}

Rafts contain $>45.0 \%$ cholesterol. Proteins are synthesized, folded in, and transported from the ER, whose membranes have a cholesterol content of $<5.0 \%$. Cholesterol and sphingolipid concentration is highest in plasma membrane, and this is apparently achieved by preventing rafts from the retrograde traffic between the Golgi complex and the ER (3-10). Hence, rafts are forwarded from the Golgi complex to the plasma membrane, where they concentrate and spread into the endocytic recycling pathways $(3,4,25)$. Diffusible sterol-binding proteins provide a rapid mechanism for shuttling cholesterol among membranes, allowing the targeted membranes to be depleted, while the vehicle membranes are enriched. Another means to facilitate transport from one membrane to another is the close contact between the two membranes. For example, in many cell types, part of the ER is in close proximity to the plasma membrane $(10,26)$, a spatial arrangement that facilitates rapid exchange of compounds due to transfer proteins. Similarly, three-dimensional reconstitution of the Golgi apparatus has revealed extensive areas of close apposition between the cis-Golgi and ER (27). The sections of the ER close to the endocytic recycling compartment (ERC) and the trans-Golgi are enriched of cholesterol-esterifying enzyme ACAT (28). This is probably required for allowing efficient delivery of cholesterol to ACAT from these cholesterol-rich membranes. The majority of membranes and cytoskeleton proteins are transported by rafts through trans-Golgi network. However, evidence is accumulating that other modalities of transport are possible, such as the one involving caveolin-1, which forms a complex with chaperon proteins delivering cholesterol from ER to the plasma membrane and bypassing the Golgi apparatus $(10,29-31)$.

\section{Epigenetic mechanisms and cancer}

The prefix 'Epi-', meaning 'besides', 'upon' or 'over', implies the existence of other phenomena beyond that indicated by the second part of the word. Epigenetic is the study of the processes by which genotypes give rise to phenotype, including the changes in gene activity occurring during development and differentiation. In addition, it concerns the mitotic inheritance of a given pattern of gene expression (nuclear inheritance) which is not based on differences in DNA sequence, and changes in gene function that are mitotically and/or meiotically heritable and that do not entail a change in DNA sequence (32). Chemical modifications imposed by environmental signals to the DNA molecule and histone proteins (nucleosome/ chromatin) affect gene function and are collectively termed as epigenetic phenomena. Examples are cytosine methylation, adenine methylation, histone phosphorylation, acetylation, methylation and ubiquitination. Therefore, genetics is the term that refers to inherited genes while epigenetic concerns the regulation of gene activity induced by chemical modification of DNA and chromatin structure proteins. It is now evident that changes occurring in cancer cells, including chromosomal instability, increased propensity to mutation, activation of oncogenes, silencing of tumour suppressor genes, and inactivation of DNA repair systems are events that require the concurrent contribution of genetic and epigenetic abnormalities. Also genomic insulator functions are involved. Insulators are DNA sequences belonging to a class of regulatory elements that define independent domains of gene function, being capable of 'insulating' when complexed with the cognate proteins. Insulator DNAs, or boundary 
elements, functionally isolate neighboring genes by blocking interactions between distal enhancers and inappropriate target promoters. Many control elements show a broad range of promoter interactions, suggesting that these elements might be affected by inappropriate transcription. In eukaryotes, motifs such as silencers, enhancers and locus control regions act over thousands of base pairs to regulate adjacent genes. The identification of a novel class of directing regulatory elements, called insulators, has provided clues into mechanisms that maintain transcription fidelity of eukaryotic genomes through the organization of independent domains of gene function by restricting enhancer and silencer functions. It is now well-established that boundary elements/insulators function to subdivide eukaryotic chromosomes into autonomous regulatory domains, and one of the underlying mechanisms is that boundaries act as barriers, preventing the processive spreading of 'active' or 'silenced' chromatin between domains. In addition, the partitioning into autonomous functional units is a consequence of an underlying structural subdivision of the chromosome into higher order 'looped' domains. In this view, boundaries are thought to delimit structural domains by interacting with each other or with some other nuclear structure.

The studies reported so far mostly provide support for the looped domain model. Proto-oncogenes and tumour suppressor genes are critical selectable targets for mutation and DNAmethylation in tumours. The readiness at which $\mathrm{CpG}$-sequences undergo alteration affect the shaping of the mutational spectra in tumours along with DNA-methylation spectra $(1,2)$. It has been found that $>290$ of the 393 codons in the p53 gene are mutated in different cancers in one allele, while the other allele is under methylation stress. Human tumours of different histological origins display different patterns of p53 mutation and methylation at $\mathrm{CpG}$-sequences. The most of them are $\mathrm{G}$ to $\mathrm{T}$ transversion, while fewer are present in skin cancer and involve $\mathrm{C}$ to $\mathrm{T}$ and $\mathrm{CC}$ to TT transition $(1,2)$.

The correlation between the status of CpG-island hypermethylation and/or mutation and tumour progression show that, for virtually every tumour type, a precise genetic alteration over time is a major driving force for neoplastic development. However, mutation of specific genes is an inefficient process, because maintenance of genomic integrity is accomplished by a complex array of DNA monitoring and repair enzymes. The genome maintenance protein team strives to ensure that DNA sequence information remains original. Karyotypic order is also guaranteed by other molecular guards, implementing the cell cycle check-points that operate at critical times in the mitotic division. Together, these systems ensure that mutations are rare events, so rare indeed that the multiple mutations known to be present in tumour cells, which are necessary for cancer progression, are low probability events within a human life span $(1,2,33)$. In fact, the most clinically relevant cancers have the tendency to occur more likely in the elderly.

5. Dynamic flux of methyl layer at the 5 '-carbon of cytosine on promoter-CpG-islands of DNA regulates gene function

Among different epigenetic mechanisms regulating gene expression, the most important are believed to be the dynamic methylation at cytosine-5'-carbon of CpG-dinucleotide and histone modifications. Overexpression of DNA (cytosine-5') methyltransferases, responsible for addition of methyl layers on DNA, hypermethylation of $\mathrm{CpG}$-islands at the regulatory regions of certain genes, global hypomethylation, and selective demethylation, are now well known to regulate transcription in association with cell activation and cancer development (34-41). The CpG- sites in these gene-associated regions are methylated rarely or demethylated very quickly in normal cells, except in inactivated X-chromosome and imprinted genes, for example $(1,37-40)$. The prevailing view is that methylation of DNA and deacetylation of histones H3 and $\mathrm{H} 4$ leads to inactivation/repression, while acetylation of histones $\mathrm{H} 1, \mathrm{H} 3, \mathrm{H} 4$ and DNA demethylation empowers activation of nucleosomes for transcription of genes (1,34-37). Repression of transcription occurs through the exclusion of proteins that affect chromatin boundaries and prevents transcription factors from binding DNA binding sites. Some proteins, such as MeCP2, MBD1, MBD2, MBD3 and MBD4 selectively bind $\mathrm{CpG}$ - and/or methyl-CpG-sequences and remodel nucleosome/chromatin to precipitate it as an inactive complex. This is accompanied by deacetylation of histones upon recruitment of histone deacetylases (HDACs) prior to binding of transcription factors, including RNA polymerase. MBD2 and MBD4 are shown to be associated with DNAdemethylation, but with different mechanisms. MBD2, probably in concert with other unknown protein complexes, removes the $-\mathrm{CH}_{3}$ group from DNA cytosine, whereas MBD4 removes the whole base (cytosine-5'C-methyl) creating an abasic site, which can be sealed with the help of secondary ligases from the mismatch repair enzyme complex $(1,36,37)$. It is now clear that abnormal methylation of $\mathrm{CpG}$-islands is not only restricted to cultured cells, but it also occurs during ageing and tumour development. While the co-existence of genome-wide hypomethylation and site-selected hypermethylation are well documented by chemical analyses of bases from total genomic DNA in gene specific DNA segment, particularly in promoters, the specific mechanism involving enzymes, co-substrates and repressor proteins is currently being explored $(1,2,34-38,41)$. Mutation in several genes encoding chromatin modifying proteins is directly involved in human diseases such as Rett syndrome caused by inactivation of $\mathrm{MeCP} 2$ and immunodeficiency-chromosome instability facial anomalies (ICF) syndrome caused by mutations in the de novo DNA methyltransferase DNMT3b. The ATRX gene, which encodes a chromatin-remodeling protein of the SNF2 family and contains a characteristic ATPase/helicase domain, also contains a cystein-rich region similar to domains present in the DNMT3b family. Mutations in this X-linked gene cause mental retardation, urogenital abnormalities, and $\alpha$-thalassemia caused by down-regulation of the $\alpha$-globin genes (42-45).

\section{Some raft component genes harbour sterol regulatory elements and CpG-islands}

Sterol regulatory element binding proteins (SREBPS), designated as a common family of transcription factors, control cholesterol and fatty acid biosynthetic pathways. SREBPs are membrane bound proteins that, due to the N-terminal active portions, can enter the nucleus to activate their target genes 
Table II. Protein components of lipid rafts which are epigenetically regulated in association with multiple cancers.

Marked fluctuations

of proteins associated Involvement Gene regulation by with cancers with lipid rafts DNA-methylation

\begin{tabular}{lll}
\hline E-cadherin & Yes & Yes, Cdh-1 and 3 \\
B-catenins & Yes & Yes \\
CD44 & Yes & Yes \\
uPA/uPAR & Yes & Yes, uPA \\
Caveolin-1 & Yes & Yes, Cav-1 \\
(AMF/PHI) & Unknown & Yes \\
Ras/Rho & Yes & Unknown, regulates \\
& & methylation of other \\
& & genes \\
VEGF-R & Yes & Yes \\
MMP-2,-7, -9 & Yes & Yes \\
Osteopontin & Yes & Unknown \\
\hline
\end{tabular}

after proteolytic cleavage, which requires sterol sensing molecules such as SREBP-activating protein (SCAP). This mechanism is crucial for sterol activity regulation. SREBPs bind and activate sterol regulatory elements (SREs) within promoters as well as some E-boxes, which makes them eligible to regulate a wide range of lipid metabolism enzymes, and a few genes encoding protein components of rafts. Three isoforms, SREBP-1a, -1c and -2, have different roles in lipid synthesis. In vivo studies using transgenic and knockout mice suggest that SREBP-1 is involved in energy metabolism, including fatty acid and glucose/insulin metabolism, whereas SREBP-2 is specific to cholesterol synthesis (46-48). Caveolin-1 has been shown to directly bind cholesterol. In addition, depletion of cellular cholesterol results in the absence of caveolae at the level of plasma membrane $(4,5,29-31)$. Interestingly, the caveolin-1 promoter has an SRE site and CpG-islands $(49,50)$. This is true also in the case of 3-hydroxy3-methylglutaryl-coenzyme-A-synthase-1 (HMGCS-1), sphingosine acyltransferase, E-cadherin and CD44 (46,51-55). The activity of these genes has been shown to be under direct control of promoter-CpG-cytosine-5'C-methylation/ demethylation flux (50-56). Promoters also contain SRE sites (46) (Tables I and II).

\section{Lipid rafts in immune escape and in new blood vessel formation (neo-angiogenesis)}

Actively growing tumour cells need the growth of novel blood vessels to take up nutrients and clean up catabolites for their survival. Neo-formed blood vessels may also become pathways for metastatic diffusion $(69,70)$. It has long been known that activated cells shed fragments of their plasma membrane into the extracellular milieu (14,15,18,19,57-59). The processes of shedding are particularly evident in actively growing tumour cells that continually need shed of membrane vesicles, in vitro and in vivo (19,57,60-67). Although several hypotheses have been suggested $(60,61$; Patra SK and Patra A, Proc Am Assoc Cancer Res 44: abs. 64, 2003), the exact mechanisms involved and their functions in shedding extracellular membrane vesicles are still not clear (19). Extracellular membrane vesicles from tumour cells (EMVTCs), derived from selected areas of plasma membrane $(14,19,62)$, appear to be enriched with raft component cholesterol, GM1, GM3 and sphingomyelin-ceramide, and contain surface antigens and proteases often present in tumour cells (19,63-67). The shed membrane smaller rafts may be aggregated by ceramide, produced locally from sphingomyelin by the action of in situ sphingomyelinase, to form larger domains of EMVTCs (68). Several studies have suggested that EMVTCs are involved in tumour growth and metastasis by playing relevant roles in the escape of tumours from immune attack and in promoting tumour cell invasion $(59,63-67)$. Surface antigens and immunesuppressing cytokine, such as transforming growth factor (TGF)- 3 present in EMVTCs (19) are important factors that protect tumours from immune attack $(7,19,59,63)$. Several proteases, including matrix metalloproteinases (MMPs) and plasminogen activators, are enriched in EMVTCs/rafts and thought to play a role in tumour cell invasion and metastasis (19,65-69). Endothelial cell migration and invasion through extracellular matrix are essential for neovascularisation, and EMVTCs/rafts enriched with sphingomyelin and MMP-2/ MMP-9 were found capable to increase the process by 3- to 5fold $(19,66,67)$. EMVTCs promote the formation of capillarylike structures of cells, similar to bFGF (19). Sphingomyelin, a lipid component of rafts/EMVTCs, stimulated the invasion of endothelial cells without the up-regulation of MMP activity (19). Tumour cells produce various cytokines and chemokines that attract various leukocytes (neutrophils, eosinophils, macrophages, dendritic cells, and mast cells), as well as lymphocytes, all of which are capable of producing a spectrum of cytokines and cytotoxic mediators including reactive oxygen species, serine and cysteine proteases, MMPs, membrane perforating agents, and soluble mediators of apoptosis, such as tumour necrosis factor (TNF)- $\alpha$, interleukins and interferons (IFNs) (33,71-73). IFNs are shown to augment DNA-methylation and apoptosis in a number of different cancer cells in vitro, and in tumours in vivo. In addition to altering the local balance of pro-angiogenic factors during melanoma development and in at least human cervical, breast and prostate carcinogenesis, angiogenesis was found to be activated in mid-stage lesions, prior to the appearance of full-blown tumours $(33,69-71)$. One common strategy for shifting the balance involves altered gene transcription. The mechanisms underlying shifts in the balance of the angiogenic regulator are poorly understood. p53 tumour suppressor protein directly regulates thrombospondin-1. Consequently, loss of p53 function, which occurs in most human tumours, can cause thrombospondin-1 levels to fall, liberating endothelial cells from its inhibitory effects (33). Loss of p53 function has been attributed to mutation in one allele and promoter inactivation by CpG-methylation of the other allele in multiple tumours (1). The vascular endothelial growth factor (VEGF) is an inducer of angiogenesis and its gene is under multiple complex transcriptional controls, including DNA-methylation. For example, activation of the Ras oncogene, or loss of the Von Hippel Lindau (VHL) tumour suppressor gene in certain cell 
types causes up-regulation of VEGF and VEGF-R expression $(33,74,75)$.

We now know that VHL, VEGF and VEGF-R promoter activity is under the direct regulation of DNA-methylation $(1,38,39,76)$. Ras oncogene induces a general demethylase activity in ras-transfected cells (77), promoting expression of many genes. It has also been showed that Ras, EGF and VEGF-R proteins are components of rafts $(6,7,49,78)$. Indeed, further research development will be the systematic study of these kinds of genetic and biochemical signals in individual types of cancer in vitro and in vivo.

\section{Lipid rafts in cell-surface architecture, cell-polarization and chemotaxis}

Some types of plasma membrane rafts such as rafts associated with tyrosine-, Src-like kinases and heterotrimeric G-protein subunits have been found to be associated with underlying cytoskeletal structures and may have important implications for signal transduction (3-7). The binding of actin is an important example of interaction of raft components with cytoplasmic proteins, which implies raft-mediated signaling (79). This interaction is also important for cell surface organization of rafts (80) and mechanical properties of cell membranes $(3,4,81)$. Actin does not bind directly to membranes, but forms protein complexes such as actin-catenin-cadherin (82), actin-(ezrin, radixin, moesin; ERM)-CD44 $(80,83,122)$ and many others, depending on tissue and cell types, where catenin and ERM-like proteins constitute a molecular bridge. Also junctional markers such as E-cadherin and CD44 can interact with the neighboring cells through their $\mathrm{N}$-terminal transmembrane domain to form a rigid cell-cell network, i.e., tissue organization of cells.

One of the most striking changes in metastatic carcinoma cells is their dramatic polarization towards blood vessels $(84,85)$. When cells polarize and begin to move in response to a chemoattractant, in most cases CD44 is directed to the rear of the cell by an actin-myosin-dependent pathway. The CD44 enriched region coincides with a large area in which lipids are more resistant to extraction by cold Triton X-100 or Lubrol, as observed in neutophils and T-lymphocytes (7,83-87). As the invading cell moves forward through extracellular matrix (ECM) barriers, the leading edge complex of enzymes, inhibitors and receptor molecules cycle continuously through adhesion, de-adhesion and proteolysis (88). The direction of tumour-cell invasion and migration can be influenced by chemoattractants and by construction of preferred adhesion pathways. Local attractants include: scatter factor/ hepatocyte growth factor (SF/HGF), which binds to the Met receptor (c-Met); proteolised matrix fragments, which are recognized by integrins, cytokines and growth factors such as epidermal growth factor (EGF); and TGF- $\beta$, released from the degraded matrix. The signals are mediated through coupling with their cognate receptors (EGF-R, TGF-R), which also are raft components, and whose gene activity (expression/repression) is tightly regulated by DNA-methylation/demethylation. Cytoskeletal rearrangement, adhesion and de-adhesion are not only required for cellular motility but are also linked to proliferation and pro-survival pathways $(33,71,89)$.

\section{Role of rafts in acquisition of metastatic potential}

The leading steps of metastasis involve LPLR interactions with ECM for decreasing mechanical stability and increasing shear forces for separation of individual cells from tumour lump. Major behavioral differences between normal and transformed cells are the abundance of collagen fibers in tumours. Several collagen and laminin genes, involved in ECM assembly (Col3a1, Col5a2 and Col6a3, and Lama5 and Lamc2), are over-expressed in tumours and tumour cell lines originating from various adenocarcinomas. The laminins are components of basement membranes that are believed to act as a mechanical barrier against carcinoma cell invasion $(71,85,89)$. Therefore, LPLR remodeling of the ECM, which is confined to the immediate pericellular environment of the cell, seems to be a necessary step in local invasion. The main enzymes that degrade the ECM and cell-adhesion proteins are proteinases such as: i) a family of secreted and membrane raft-anchored MMPs; ii) tissue serine proteinases such as urokinase type plasminogen activator (uPA), thrombin and plasmin (89). In several experimental models uPA has been shown to function through its receptor (uPAR), which again is a raft component (Table I). Integrins, tetraspanins, uPAR and rafts conjointly cooperate to confine the serine proteinase uPA to the invading pseudopodia. UPAR is an adhesion receptor for vitronectin, and also interacts with integrin B-chains. Proteolysis of ECM proteins modifies integrin-mediated anchorage, focal adhesion and cytoskeletal architecture, triggering signaling molecules such as focal adhesion kinase (FAK) and motility factors such as AMF/PHI. Remarkably, it has been shown that MMP and UPAR gene activity is directly controlled by DNA-methylation and demethylation of their respective CpG-island-rich promoters at cytosine-5'-carbon. Moreover, MMPs and uPAR are components of rafts (90-94).

\section{Conclusion and perspectives}

Many proteins involved in important processes including signal transduction and structural components are assembled in rafts. As a consequence of their interaction with rafts, several cell surface enzymes and marker proteins show an increase in catalytic efficiency and in/out transport of molecules, and signal transduction across membranes is activated (3-7,95-97). Thus, rafts might play a coordinating role for these phenomena. Interestingly, most of these enzymes/proteins either recognize specific antigens or have limited signal transduction specificity. An intriguing possibility is that raft-integrated proteins, for which changes in structure-function after binding with other molecules are essential steps for their action, use rafts to interact with their cognate components (3-9,57-75,78-88). In a similar way, rafts appear to be able to facilitate transportation of cell junction proteins from cytosol to membranes. Raft trafficking seems to be a way for the cell to recruit and transport proteins to a particular place at a particular moment of cell life $(5,7,79-88)$. Studies have shown that cholesterol, sphingolipids and gangliosides, all raft components, are up-regulated in aggressive metastasized tumours in comparison to benign tumours at early stage $(11-18,57,58,60,61,62,63,65-68)$. In many cases it has been shown that the level of expression of cell adhesion molecules and metastasis protein factors 
associated with rafts are differently regulated in growing, progressing and metastasizing tumours. These genes are mostly inactivated by DNA-methylation (Table II) $(1,36-39,42,50$ 56,76,82,90-92,98,99-110; Ou J-N, et al, Proc Am Assoc Cancer Res 44: abs. 209, 2003), and their reactivations certainly need demethylation activity (1,36-41). For instance, mRNA and protein expression of caveolin-1, a major component of caveolae proteins, is frequently lost in multiple cancers. Caveolin-1 is known to be a tumour suppressor gene. Current results are consistent with the dual function of caveolin-1 both as a tumour suppressor gene and metastasis-promoting gene. At cancer onset, the calveolin-1 gene is repressed by DNA-methylation, while re-expression by demethylation occurs prior to metastasis $(50,56,108)$. CD44 associated to lipid rafts is known to be involved in re-organization of highly dynamic structures of cytoskeleton when cells respond to extracellular stimuli by division and/or changes in shape or activity (83). mRNA and protein expression of CD44 is frequently lost by DNA-methylation in multiple cancers at the early stage of tumour progression $(36,51,53,55,99-101)$. Again, re-expression of the CD44 gene is necessary for metastatic diffusion of many tumours $(52,98,100,101,109,111)$. E-cadherin transmembrane glycoprotein is a calcium-dependent cell-cell adhesion molecule, known to play a key role in the maintenance of tissue integrity by forming a complex with catenin. E-cadherin is eventually tagged to actin cytoskeleton through catenins. Because loss of E-cadherin expression results in disruption of cellular clusters, it has been postulated that E-cadherin functions as a tumour suppressor gene. mRNA and protein expression of E-cadherin is frequently lost by DNA-methylation in multiple cancers at the early stage of tumour progression $(36,54,82,101-107,110,117)$. Also in this case, re-expression of E-cadherin has been shown to be clinically significant at the metastatic foci of many cancers (101,103,105-107). Persistent expression of E-cadherin was observed in breast cancer $(71,102)$.

The most damaging change during cancer progression is the switch from a locally growing tumour to a metastatic killer (112). This involves many steps in which lipids are integral components of molecular structures allowing biochemical interactions with proteins and enzymes. A list of phenomena in which protein-lipid interaction are fundamental include environmental threats such as oncogene activation and proliferation of transformed cells, acquired ability of protection against the immune system, release of angiogenic factors, local invasion and destruction of extracellular matrix, detachment and migration from the tumour lump and penetration through the blood vessel wall, arrest of the cells in the lumen of small blood vessels or lymphatics, and docking and formation of fusion clump to distant organs by reverse penetration of blood vessels (33). Rafts are platforms for cell surface antigens and adhesion molecules. Accordingly, they play crucial roles in cancer cell polarization and signaling. For instance, a recent review (126) focused on cholesterol-rich membrane rafts as potential sites of processing of non-genomic signals that involve androgen as well as other classical steroid receptors (SRs). However, although the molecular details as well as the biological meaning of non-genomic action of steroids are still investigated and debatable, the familiar loss of control of receptors such as androgen receptor (AR) and estrogen receptor is a clinically relevant priority area of investigation. The main molecular target for testosterone is AR, which is a member of the nuclear receptor family of ligand-induced transcription factors. It binds to a specific chromatin region bearing androgen responsive elements (ARE) in concert with other transcriptional regulators, and controlling the transcription of target genes (126). The activation of SRs was thought to be dependent on the availability of the specific ligand (hormone), but subsequent data on DNA-methylation of the target gene promoter have added new insights into the steroid function in cancer progression (127-129).

It has been shown that lovastatin (an inhibitor of cholesterol biosynthesis) inhibits mammary carcinoma metastasis and that cyclodextrin (which can efflux cholesterol from cells and membranes) decreases apical transport of raft-associated proteins, while latrunculin-B disrupts actin cytoskeleton (hence raft redistribution is deregulated), thus preventing the activated T-cell polarity. All this indicates that gangliosidecholesterol-rafts play definite roles in the above cellular processes $(88,108,112-114,115)$. For instance, metastatic potential of mouse Lewis lung cancer cells is regulated via ganglioside GM1 by modulating the MMP-9 localization in rafts. Among adhesion molecules, only integrin B1 was detected in glycolipid-enriched microdomain (GEM)/rafts with stronger intensity in highly metastatic cell lines and low staining in GM1-expressing cells. Taken together, integrins may very likely be enriched in GEM/rafts in which GM1 levels are decreased. As a consequence, MMP-9 is recruited to the GEM/rafts, resulting in efficient secretion and activation, and eventually facilitating invasion and metastatic potentials (130). In this context, accumulation of lipids and cholesterol in solid tumours, including prostate cancer has been observed $(11,96,126,131)$. It must be pointed out that blood cholesterol is a major source of plasma membrane cholesterol as a result of cellular absorption of lipoprotein from serum, thus membrane cholesterol content is substantially dependent on diet (131). It is known that rates of prostate and other cancers are significantly affected by exogenous factors, including the western diet that implies consumption of red meat and/or excessive animal fat (132), whereas reduced intake of animal fat and red meat along with consumption of poly-phenolic compounds (curcumin from turmeric, catechins from green tea, and many others like zinger, cumin, neem, aswagandha, that have all been found to reduce cholesterol), besides other molecular reasons still to be investigated, are considered important for prevention of cancer progression and currently tested in in vivo animal models or clinically $(11,126,132-134)$. Many raft component genes are epigenetically regulated by dynamic flux of methyl layer at cytosine-5'C of promoterCpG-islands of DNA. CpG-island methylation is one of many epigenetic switches, and plays critical roles in controlling expression of raft proteins involved in tumour growth and cancer metastasis. Treatment of cells with histone deacetylase inhibitor trichostatin A was found capable of enhancing lipid rafts (135). This is direct proof of epigenetic modulation of raft components. Since the raft component proteins play their role by association-dissociation with rafts, targeting lipids such as cholesterol or sphingomyelin along with proteins might be the new frontier for novel therapeutic intervention for cancer. 


\section{Acknowledgements}

Contract grant sponsors: FIL 2006, University of Parma, Italy; Abo Project 2006, Italy; AICR (UK) Grant No. 06-711; Istituto Nazionale Biostrutture e Biosistemi (INBB), Roma, Italy. We apologise for many other important contributions that we have not been able to discuss due to space limitations. We also thank Professor Subhas C. Santra, Department of Environmental Science, University of Kalyani, West Bengal (India) for his helpful contribution in the discussion on these research issues.

\section{References}

1. Jones PA and Vogt PK (eds): DNA methylation and cancer. In Current Topics in Microbiology and Immunology. Springer, 249: pp1-169, 2000.

2. Jaenisch R and Bird A: Epigenetic regulation of gene expression - how the genome integrates intrinsic and environmental signals (Review). Nat Genetics 33 (suppl): S245-S254, 2003.

3. Edidin M: The state of lipid rafts: from model membranes to cells. Annu Rev Biophys Biomol Struct 32: 257-283, 2003.

4. Sharma P, Varma R, Sarasij RC, Ira-Gousset K, Krishnamoorthy G, Rao M and Mayor S: Nanoscale organization of multiple GPIanchored proteins in living cell membranes. Cell 116: 577-589, 2004.

5. Simons K and Ikonen E: How cells handle cholesterol. Science 290: $1721-1726,2000$

6. Simons $\mathrm{K}$ and Toomre D: Lipid rafts and signal transduction: nature reviews. Mol Cell Biol 1: 31-41, 2000.

7. Dykstra M, Cherukuri A, Sohn HW, Tzeng S-J and Pierce SK: Location is everything: lipid rafts and immune cell signaling. Annu Rev Immunol 21: 457-481, 2003.

8. Gronborg M, Kristiansen TZ, Iwahori A, Chang R, Reddy R, Sato N, Molina H, Jensen ON, Hruban RH, Goggins MG Maitra A and Pandey A: Biomarker discovery from pancreatic cancer secretome using a differential proteomic approach. Mol Cell Proteomics 5: 157-171, 2006.

9. Simons K and Enhalt R: Cholesterol, lipid rafts and disease [Biol \& Biochem of Cholesterol (Perspective)]. J Clin Invest 110: 597-603, 2002.

10. Maxfield FR and Wustner D: Intracellular cholesterol transport [Biol \& Biochem of Cholesterol (Perspective)]. J Clin Invest 110: 891-898, 2002.

11. White RM: On the occurrence of crystals in tumours. J Pathol Bacteriol 13: 3-10, 1909

12. Yasuda M: Lipid metabolism of tumours. Proc Soc Exp Biol Med 27: 944-945, 1930.

13. Swyer GMI: The cholesterol content of normal and enlarged prostates. Cancer Res 2: 372-375, 1942

14. Lerner MP, Lucid SW, Wen GJ and Nordquist RE: Selected area membrane shedding by tumour cells. Cancer Lett 20 : 125-130, 1983.

15. Hoessli D and Runger-Brandle E: Association of specific cell surface glycoproteins with a Triton X-100-resistant complex of plasma membrane proteins isolated from T-lymphoma cells. Exp Cell Res 156: 239-250, 1985.

16. Le Bivic A, Sari H, Reynier M, Lebec S and Bardin F: Differences in lipid characteristics of autologous human melanoma cell lines with distinct biological properties. J Natl Cancer Inst 79: 1181-1188, 1967

17. Dahiya R, Boyle B, Goldberg BC, Yoon WH, Knoety B, Chen K Yen TS, Blumenfeld W and Narayan P: Metastasis associated alteration in phospholipids and fatty acids of human prostatic adenocarcinoma cell lines. Biochem Cell Biol 70: 548-554, 1992.

18. Deng W, Li R and Ladisch S: Influence of cellular ganglioside depletion on tumour formation. J Natl Cancer Inst 92: 912-917, 2000.

19. Kim CW, Lee HM, Lee TH, Kang C, Kleinman HK and Gho YS Extracellular membrane vesicles from tumour cells promote angiogenesis via sphingomyelin. Cancer Res 62: 6312-6317, 2002 .

20. Brown DA and Rose JK: Sorting of GPI-anchored protein to glycolipids-enriched membrane subdomains during transport to the apical cell surface. Cell 68: 533-544, 1992.
21. Patra SK, Alonso A and Goni FM: Detergent solubilizations of phospholipid bilayer in the gel state: the role of polar and hydrophobic forces. Biochim Biophys Acta 1373: 112-118, 1998

22. Patra SK and Pal MK: Spectroscopic probe of the individual and combined effect of Triton-X-100 and chloroform on human and bovine serum albumins and serum albumin-bilirubin complexes. Eur J Biochem 246: 658-664, 1997.

23. Patra SK, Alonso A, Arrondo JLR and Goni FM: Liposome containing sphingomyelin and cholesterol: detergent solubilization and infrared spectroscopic studies. J Liposome Res 9: 247-260, 1999.

24. Foster LJ, De Hoog CL and Mann M: Unbiased quantitative proteomics of lipid rafts shows high specificity for signaling factors. Proc Natl Acad Sci USA 100: 5813-5818, 2003.

25. Chatterjee S, Smith ER, Hanada K, Stevens VL and Mayor S: GPI anchoring leads to sphingolipid-dependent retention of endocytosed proteins in the recycling endosomal compartment. EMBO J 20: 1583-1592, 2001

26. Putney J: 'Kissin' cousins': intimate plasma membrane-ER interactions underlie capacitative calcium entry. Cell 99: 5-8, 1999.

27. Ladinsky MS, Mastronarde DN, McIntosh JR, Howell KE and Staehelin LA: Golgi structure in three dimensions:functional insights from the normal rat kidney cell. J Cell Biol 144: $1144,1999$.

28. Khelef N, Soe TT, Quehenberger O, Beatini N, Tabas I and Maxfield FR: Enrichment of acyl coenzyme A: cholesterol O acyl transferase near trans-Golgi network and endocytic recycling compartment. Arterioscler Thromb Vasc Biol 20: 1769-1776, 2000 .

29. Ikonen E and Parton R: Caveolins and cellular cholesterol balance. Traffic 1: 212-217, 2000.

30. Fielding C, Bist A and Fielding P: Intracellular cholesterol transport in human skin fibroblasts. Biochemistry 38: 2506-2513, 1999.

31. Wittenbogaard A and Smart E: Palmitoylation of caveolin-1 is required for cholesterol binding, chaperon complex formation and rapid transport of cholesterol to caveolae. J Biol Chem 275 : 25595-25599, 2000

32. Wu C-T and Moriss JR: Genes, genetics and epigenetics: a correspondence. Science 293: 1103-1105, 2001.

33. Hanahan D and Weinberg RA: The hallmarks of cancer. Cell 100: 57-70, 2000

34. Fuks F, Burgers WA, Brehm A, Hughes-Davies L and Kouzarides T: DNA methyltransferase DNMT1 associates with histone deacetylase activity. Nat Genet 24: 88-91, 2000.

35. Patra SK, Patra A and Dahiya R: Histone deacetylase and DNA methyltransferase in human prostate cancer. Biochem Biophys Res Commun 287: 705-713, 2001

36. Patra SK, Patra A, Zhao H and Dahiya R: DNA methyltransferase and demethylase in human prostate cancer. Mol Carcinogenesis 33: 163-167, 2002.

37. Patra SK, Patra A, Zhao H, Carrol P and Dahiya R: Methyl-CpGDNA binding proteins in human prostate cancer: expression of CXXC sequence containing MBD1 and repression of MBD2 and MeCP2. Biochem Biophys Res Commun 302: 759-766, 2003.

38. Jones PA and Baylin SB: The fundamental role of epigenetic events in cancer. Nat Rev Genet 3: 415-428, 2002.

39. Szyf M, Knox DJ, Milutinovic S, Slack AD and Araujo FD: How does DNA methyltransferase cause oncogenic transformation? Ann NY Acad Sci 910: 156-174, 2000.

40. Bruniquel D and Schwartz RH: Selective, stable demethylation in interleukin-2 gene enhances transcription by an active process. Nat Immunol 4: 235-240, 2003.

41. Ng H-H, Jeppesen P and Bird A: Active repression of methylated genes by the chromosomal protein MBD1. Mol Cell Biol 20 1394-1406, 2000.

42. Feinberg AP, Oshimura M and Barrett JC: Epigenetic mechanism in human disease. Cancer Res 62: 6784-6787, 2002.

43. Amir RE, van den Veyver IV, Wan M, Tran CQ, Francke U and Zoghbi HY: Rett syndrome is caused by mutations in X-linked $\mathrm{MeCP} 2$, encoding methyl-CpG-binding protein 2 . Nat Genet 23 . 185-188, 1999.

44. Xu GL, Bestor TH, Bourc'his D, Hiseh CL, Tommerup N, Bugge M, Hulten M, Qu X, Russo JJ and Viegas-Pequignot E: Chromosome instability and immunodeficiency syndrome caused by mutations in a DNA methyltransferase gene. Nature 402 : 187-191, 1999. 
45. Gibbons RJ, McDwell TL, Raman S, O'Rourke DM, Garrick D, Ayyub H and Higgs DR: Mutations in ATRX, encoding a SWI/SNF-like protein, cause diverse changes in the pattern of DNA methylation. Nat Genet 24: 368-371, 2000 .

46. Shimano H: Sterol regulatory element-binding proteins (SERBPs)-transcriptional regulators of lipid synthetic genes. Prog Lipid Res 40: 439-452, 2001.

47. Yang T, Espenshade PJ, Wright ME, Yabe D, Gong Y, Aebersold R, Goldstein JL and Brown MS: Crucial step in cholesterol homeostasis: sterols promote binding of SCAP to INSIG-1, a membrane protein that facilitate retention of SREBPs in ER. Cell 110: 489-500, 2002.

48. Brown MS and Goldstein JL: A proteolytic pathway that controls the cholesterol content of membranes, cells and blood. Proc Natl Acad Sci USA 96: 11041-11048, 1999.

49. Galbiati F, Razani B and Lisanti MP: Emerging themes in lipid rafts and caveolae. Cell 106: 403-411, 2002.

50. Wiechen K, Diatchenko L, Agoulink A, Scharff KM, Schober H, Arlt K, Zhumabayeva B, Siebert PD, Dietel M, Schafer R and Sers C: Caveolin-1 is down-regulated in human ovarian carcinoma and Acts as candidate tumour suppressor gene. Am J Pathol 159: 1635-1643, 2001

51. Lou W, Krill D, Dhir R, Becich MJ, Dong J-T, Frierson HF Jr, Isaacs WB, Isaacs JT and Gao AC: Methylation of CD44 metastasis suppressor gene in human prostate cancer. Cancer Res 59: 2329-2331, 1999.

52. Weber GF, Bronson RT, Ilagan J, Cantor H, Schmits R and Mak TW: Absence of the CD44 gene prevents sarcoma metastasis. Cancer Res 62: 2281-2286, 2002.

53. Hasegawa M, Nelson HH, Peters E, Ringstrom E, Posner M and Kelsey KT: Patterns of gene promoter methylation in squamous cell cancer of the head and neck. Oncogene 21: 4231-4236, 2002.

54. Graff JR, Gabrielson E, Fuji H, Baylin SB and Herman JG: Methylation patterns of the E-cadherin (CDH gene) 5'-CpG- island are unstable and reflect the dynamic, heterogeneous loss of Ecadherin expression during metastatic progression. J Biol Chem 275: 2727-2732, 2000.

55. Kito H, Suzuki H, Ichikawa T, Sekita N, Kamia N, Akakura K, Igarashi T, Nakayama T, Watanabe M, Harigaya $\mathrm{K}$ and Ito $\mathrm{H}$ : Hypermethylation of the CD44 gene is associated with progression and metastasis of human prostate cancer. Prostate 49: $110-115,2001$

56. Cui J, Rohr LR, Swanson G, Speights VO, Maxwell T and Brothman AR: Hypermethylation of the caveolin-1 gene promoter in prostate cancer. Prostate 46: 249-256, 2001.

57. Combes V, Simon AC, Grau GE, Arnoux D, Camoin L, Sabatier F, Mutin M, Sanmareo M, Sampol J and DignatGeorge F: In vitro generation of endothelial microparticles and possible prothrombic activity in patients with lupus anticoagulant. J Clin Investig 104: 93-102, 1999.

58. Barry OP, Pratico D, Lawson JA and FitzGerald GA: Transcellular activation of platelets and endothelial cells by bioactive lipids in platelet microparticles. J Clin Invest 99: 2118-2127, 1997.

59. Mackenzie A, Wilson HL, Kiss-Toth E, Dower SK, North RA and Surprenant A: Rapid secretion of interleukin-1ß by microvesicles shedding. Immunity 15: 825-835, 2001.

60. Taylor DD and Black PH: Shedding of plasma membrane fragments. In: Developmental Biology. Steinberg M (ed). Plenum Publ Corp., NY, pp33-57, 1986.

61. Cassara D, Ginestra A, Dolo V, Miele M, Caruso G, Lucania G and Vittorelli ML: Modulation of membrane shedding in 8701 human breast carcinoma cells. J Submicrosc Cytol Pathol 30: 45-43, 1998.

62.Van Blitterswijk WJ, De Veer G, Krol JH and Emmelot P: Comparative analysis of purified plasma membranes and shed extracellular membrane vesicles from normal murine thymocytes and leukemic GRSL cells. Biochim Biophys Acta 688: 495-504, 1982.

63. Poutsiaka DD, Taylor DD, Levy EM and Black PH: Inhibition of recombinant interferon- $\gamma$-induced Ia antigen expression by shed B16F10 melanoma cell membrane vesicles. J Immunol 134: 145-150, 1985.

64. Wolfers J, Lozier A, Raposo G, Regnault A, Thery C, Masurier C, Flament C, Pouzieux S, Faure F, Tursz T, Angevin E, Amigorena $S$ and Zitvogel L: Tumour-derived exosomes are a source of shared tumour rejection antigens for CTL crosspriming. Nat Med 7: 297-303, 2001.
65. Dolo V, D'Ascenzo S, Violini S, Pompucci L, Festuccia C, Ginestra A, Vittorelli ML, Canevari S and Pavan A: Matrix degraded proteinases are shed in membrane vesicles by ovarian cancer cells in vivo and in vitro. Clin Exp Metastasis 17: 131-140, 1999.

66. Ginestra A, Monia S, Seghezzi G, Dolo V, Nagase H, Mignatti P and Vittorelli ML: Urokinase plasminogen activator and gelatinases are associated with membrane vesicles shed by human HT1080 fibrosarcoma cells. J Biol Chem 272: 17216-17222, 1997.

67. Dolo V, Ginestra A, Cassara D, Violini S, Luciania G, Torrisi G, Nagase H, Canevari S, Pavan A and Vittorelli ML: Selective localization of matrix metalloproteinase 9, B1 integrins and human lymphocyte antigen class I molecules on membrane vesicles shed by $8701-\mathrm{BC}$ breast carcinoma cells. Cancer Res 58 4468-4474, 1998.

68. Cremesti AE, Goni FM and Kolesnick R: Role of sphingomyelinase and ceramide in modulating rafts: do biophysical properties determine biologic outcome? FEBS Lett 531: 47-53, 2002.

69. Folkman J and Shing Y: Angiogenesis. J Biol Chem 267: 10931-10934, 1992.

70. Gho YS, Kleinman HK and Sosne G: Angiogenic activity of human soluble intercellular adhesion molecule-1. Cancer Res 59: $5128-5132,1999$.

71. Coussens LM and Werb Z: Inflammation and cancer. Insight review. Nature 420: 860-867, 2002.

72. Kuper H, Adami HO and Trichopoulos D: Infections as a major preventable cause of human cancer. J Int Med 248: 171-183, 2000.

73. Wahl LM and Kleinman HK: Tumour associated macrophages as targets for cancer therapy. J Natl Cancer Inst 90: 1583-1584, 1998.

74. Rak J, Filmus J, Finkenzeller G, Grugel S, Marme D and Kerbel RS: Oncogenes as inducers of tumour angiogenesis. Cancer Metastasis Rev 14: 263-277, 1995.

75. Maxwell PH, Wiesener MS, Chang G-W, Clifford SC, Vaux EC, Cockman ME, Wykoff CC, Pugh CW, Maher ER and Ratcliff PJ: The tumour suppressor protein VHL targets hypoxia-inducible factors for oxygen dependent proteolysis. Nature 399: 271-275, 1999

76. Yamada Y: Aberrant methylation of the vascular endothelial growth factor receptor-1 gene in prostate cancer. Cancer Sci (JCA) 94: 536-539, 2003.

77. Szyf M, Theberge J and Bozovic V: Ras induces a general DNA demethylation activity in mouse embryonal P19 cells. J Biol Chem 270: 12690-12696, 1995.

78. Mira E, Lacalle RA, Buesa JM, De Buitrago GG, JimenezBaranda S, Gomez-Mouton C, Martinez AC and Manes S: Secreted MMP9 promotes angiogenesis more efficiently than constitutive active MMP9 bound to the tumour cell surface. J Cell Sci 117: 1847-1857, 2004

79. Harder T, Kellner R, Parton RG and Gruenberg J: Specific release of membrane bound annexin II and cortical cytoskeletal elements by sequestration of membrane cholesterol. Mol Cell Biol 8: 533-545, 1997.

80. Dustin ML: Shmoos, rafts and uropods - the many facets of cell polarity. Cell 110: 13-18, 2002

81. Suzuki K and Sheetz MP: Binding of cross-linked glycosylphosphatidyl-inositol-anchored proteins to discrete actinassociated sites and cholesterol dependent domains. Biophys J 81: 2181-2189, 2001.

82. Jiang WG and Mansel RE: E-cadherin complex and its abnormalities in human breast cancer. Surg Oncol 9: 151-171, 2000.

83. Foger N, Marhaba R and Zoller M: Involvement of CD44 in cytoskeleton rearrangement and raft reorganization in T cells. J Cell Sci 114: 1169-1178, 2000.

84. Maxfield FR: Plasma membrane microdomains. Curr Opin Cell Biol 14: 483-487, 2002.

85. Wyckoff JB, Jones JG, Condeelis JS and Segall JE: A critical step in metastasis: in vivo analysis of intravasation at the primary tumour. Cancer Res 60: 2504-2511, 2000.

86. Wang W, Wyckoff JB, Frohlich VC, Oleynikov Y, Huttelmaier S, Zavadil J, Cermak L, Bottinger EP, Singer RH, White JG, Segall JE and Condeelis JS: Single cell behavior in metastatic primary mammary tumours correlated with gene expression patterns revealed by molecular profiling. Cancer Res 62: 6278-6288, 2002

87. Seveau S, Eddy R, Maxfield FR and Pierini L: Cytoskeleton dependent membrane domain segregation during neutrophil polarization. Mol Cell Biol 12: 3550-3562, 2001. 
88. Gomez-Mouton C, Abad JL, Mira E, Lacalle RA, Gallardo E, Jimenez-Baranda S, Illa I, Bernad A, Manes S and Martinez AC: Segregation of leading-edge and uropod components into specific lipid rafts during T cell polarization. Proc Natl Acad Sci USA 98: 9642-9647, 2001.

89. Liotta LA and Khon EC: The microenvironment of the tumourhost interface. Insight review. Nature 411: 375-379, 2001.

90. Sato N, Maehara N, Su GH and Goggins M: Effects of 5-Aza2 -deoxycytidine on matrix metalloproteinase expression and pancreatic cancer cell invasiveness. J Natl Cancer Inst 95: 327-330, 2003

91. Guo Y, Pakneshan P, Gladu J, Slak A, Szyf M and Rabbani SA: Regulation of DNA methylation in human breast cancer: effect on the urokinase-type plasminogen activator gene production and tumour invasion. J Biol Chem 277: 41571-41579, 2002.

92.Pakneshan P, Szyf M, Farias-Eisner R and Rabbani SA: Reversal of the hypomethylation status of urokinase (uPA) promoter blocks breast cancer growth and metastasis. J Biol Chem 279: 31735-31744, 2004

93. Sitrin RG, Johnson DR, Pan PM, Harsh DM, Huang J, Petty HR and Blackwood RA: Lipid rafts compartmentalization of urokinase receptor signaling in human neutrophils. Am J Respir Cell Mol Biol 30: 233-241, 2004.

94. Rozanov DV, Deryugina EI, Monosov EZ, Marchenko ND and Strongin AY: Aberrant, persistent inclusion into lipid rafts limits the tumourigenic function of membrane type-1 matrix metalloproteinase in malignant cells. Exp Cell Res 293: 81-95, 2004.

95. Rahn JJ, Shen Q, Mah BK and Hugh JC: MUC1 initiates a calcium signal after ligation by intercellular adhesion molecule-1. J Biol Chem 279: 29386-29390, 2004.

96.Zhuang L, Lin J, Lu ML, Solomon KR and Freeman MR: Cholesterol-rich lipid rafts mediate Akt-regulated survival in prostate cancer cells. Cancer Res 62: 2227-2231, 2002.

97.Los DA and Murata N: Regulation of enzymatic activity and gene expression by membrane fluidity. Science's STKE www.stke.org/cgi/content/full/oc_sigtrans; 2000/62/pe 1, 2000 .

98. Verkaik NS, Trapman J, Romijn JC, van der Kwast TH and van Steenbrugge GJ: Down-regulation of CD44 expression in human prostatic carcinoma cell lines is correlated with DNA hypermethylation. Int J Cancer 80: 439-443, 1999.

99. Hyman R: Lack of a consistent relationship between demethylation of the CD44 promoter and CD44 expression. Immunogenetics 53: 914-924, 2002.

100. Shiras A, Bhosale A, Patekar A, Shepal V and Shastry P: Differential expression of CD44(s) and variant isoforms v3, v10 in three-dimensional cultures of mouse melanoma cell lines. Clin Exp Metastasis 19: 445-455, 2002.

101.Bankfalvi A, KraBort M, Buchwalow IB, Vegh A, Felszeghy E and Piffko J: Gains and loses of adhesion molecules (CD44, Ecadherin and B-catenin) during oral carcinogenesis and tumour progression. J Pathol 198: 343-351, 2002.

102. Kleer CG, van Golen KL, Braun T and Merajver SD: Persistant E-cadherin expression in inflammatory breast cancer. Mod Pathol 14: 458-464, 2001

103. Karube H, Masuda H, Ishii Y and Takayama T: E-cadherin expression is inversely proportional to tumour size in experimental liver metastasis. J Surg Res 106: 173-178, 2002.

104. Alpaugh ML, Tomlinson JS, Kasraeian S and Barsky SH: Cooperative role of E-cadherin sialyl-Lewis X/A-deficient MUC1 in the passive dissemination of tumour emboli in inflammatory breast carcinoma. Oncogene 21: 3631-3643, 2002.

105. Ikeguchi M, Makino M and Kaibara N: Clinical significance of E-cadherin-catenin complex expression in metastatic foci of colorectal carcinoma. J Surg Oncol 77: 201-207, 2001

106. Kase S, Sugio K, Yamazaki K, Okamoto T, Yano T and Sugimachi K: Expression of E-cadherin and $\beta$-catenin in human non-small cell lung cancer and the clinical significance. Clin Cancer Res 6: 4784-4796, 2000.

107.Liu J, Ikeguchi M, Nakamura S and Kaibara N: Re-expression of the cadherin-catenin complex in lymph nodes with metastasis in advanced gastric cancer: the relationship with patient survival. J Exp Clin Cancer Res 21: 65-71, 2002.

108. Ho C-C, Huang P-H, Huang H-Y, Chen Y-H, Yang P-C and Hsu S-M: Up-regulated caveolin-1 accentuates the metastasis capability of lung adenocarcinoma by inducing filopodia formation. Am J Pathol 161: 1647-1656, 2002.
109. Kogerman P, Sy M-S and Culp LA: Counter-selection for overexpressed human CD44s primary tumour versus lung metastases in mouse fibrosarcoma model. Oncogene 15: 1407-1416, 1997.

110. Ribeiro-Filho LA, Franks J, Sasaki M, Shiina H, Li L-C, Nojima D, Arap S, Carroll P, Enokida H, Nakagawa M, Yonezawa S and Dahiya R: CpG hypermethylation of promoter region and inactivation of E-cadherin gene in human bladder cancer. Mol Carcinog 34: 187-198, 2002.

111. Shiratori H, Koshino T, Uesugi M, Nitto H and Saito T: Accleration of lung metastasis by up-regulation of CD44 expression in osteosarcoma-derived cell transplanted mice. Cancer Lett 170: 177-182, 2001

112.Weber GF: The metastasis gene osteopontin: a candidate target for cancer therapy. Biochim Biophys Acta 1552: 61-85, 2001.

113. Sporn MB: The war on cancer. Lancet 347: 1377-1381, 1996.

114. Farina HG, Bublik DR, Alonso DF and Gomez DE: Lovastatin alters cytoskeleton organization and inhibits experimental metastasis of mammary carcinoma cells. Clin Exp Metastasis 19: $551-559,2002$

115.Inokuchi J-I, Uemura S, Kabayama K and Igarashi $\mathrm{Y}$ : Glycosphingolipid deficiency affects functional microdomain formation in Lewis lung carcinoma cells. Glycoconjugate J 17 $239-245,2000$

116. Etiene-Manneville S and Hall A: Rho GTPases in cell biology. Nature 420: 629-635, 2002.

117. Rios-Doria J, Day KC, Kuefer R, Rashid MG, Chinnaiyan AM, Rubin MA and Day ML: The role of calpain in the proteolytic cleavage of E-cadherin in prostate and mammary epithelial cells. J Biol Chem 278: 1372-1379, 2003.

118.Zetter BR and Banyard J: Cancer: the silence of the genes. Nature 419: 572-573, 2002.

119. Prior IA, Muncke C, Parton RG and Hancock JF: Direct visualization of Ras proteins in spatially distinct cell surface microdomains. J Cell Biol 160: 165-170, 2003.

120. Tsutsumi S, Gupta SK, Hogan V, Collard JG and Raz A: Activation of small GTPase Rho is required for autocrine motility factor signaling. Cancer Res 62: 4484-4490, 2002.

121. Yamada KM and Clark K: Cell biology - survival in three dimensions. Nature 419: 790-791, 2002.

122. Spec O, Hughes SC, Noren NK, Kulikauskas RM and Fehon RG: Moesin functions antagonistically to the Rho pathway to maintain epithelial integrity. Nature 421: 83-87, 2003.

123. Hove JR, Koster RW, Forouhar AS, Acevedo-Bolton G Fraser SE and Gharib M: Intracardiac fluid forces are essential epigenetic factor for embryonic cardiogenesis. Nature 421: 172-177, 2003

124. Hatta M, Nagai H, Okino K, Onda M, Yoneyama K, Ohta Y, Nakayama H, Araki T and Emi M: Down-regulation of members of glycolipid-enriched membrane raft gene family, MAL and BENE, in cervical squamous cell cancers. J Obstet Gynaecol Res 30: 53-58, 2004.

125. Sathyanarayana UG, Padar A, Huang CX, Suzuki M, Shigematsu H, Bekele BN and Gazdar AF: Aberrant promoter methylation and silencing of laminin-5-encoding genes in breast carcinoma. Clin Cancer Res 9: 6389-6394, 2003.

126. Freeman MR, Cinar B and Lu ML: Membrane rafts as potential sites of non-genomic hormonal signaling in prostate cancer. Trends Endocrin Metabol 16: 273-279, 2005.

127. Sasaki M, Tanaka Y, Perinchery G, Dharia A, Kotcherguina I, Fujimoto $\mathrm{S}$ and Dahiya R: Methylation and inactivation of estrogen, progesterone and androgen receptors in prostate cancer. J Natl Cancer Inst 94: 384-390, 2002.

128. Nojima D, Li LC, Dharia A, Perinchery G, Ribeiro-Filho L, Yen TS and Dahiya R: CpG hypermethylation of the promoter region inactivates the estrogen receptor-beta gene in patients with prostate carcinoma. Cancer 92: 2076-2083, 2001

129. Li LC, Chui R, Nakajima K, Oh BR, Au HC and Dahiya R: Frequent methylation of estrogen receptor in prostate cancer: correlation with tumor progression. Cancer Res 60: 702-706, 2000.

130.Zhang Q, Furukawa K, Chen HH, Sakakabara T, Urano T and Furukawa K: Metastatic potential of Mouse Lewis lung cancer cells is regulated via ganglioside GM1 by modulating the matrix metalloprotease-9 localization in lipid rafts. J Biol Chem 281: $18145-18155,2006$

131. Gray DF, Hansen PS, Doohan MM, Hool LC and Rasmussen HH: Dietary cholesterol affects $\mathrm{Na}^{+}-\mathrm{K}^{+}$pump function in rabbit cardiac myocytes. Am J Physiol 272: H1680-H1689, 1997. 
132. Michaud DS, Augustsson K, Rimm EB, Stampfer MJ, Willet WC and Giovannucci EA: A prospective study of intake of animal products and risk of prostate cancer. Cancer Causes Control 12: 557-567, 2001

133. Fujimura Y, Yamada $\mathrm{K}$ and Tachibana $\mathrm{H}$ : A lipid raftassociated $67 \mathrm{kDa}$ laminin receptor mediates suppressive effect of epigallocatechin-3-O-gallate on FcepsilonRI expression. Biochem Biophys Res Commun 336: 674-681, 2005.
134. Bettuzzi S, Brausi M, Rizzi F, Castagnetti G, Peracchia G and Corti A: Chemoprevention of human prostate cancer by oral administration of green tea catechins in volunteers with highgrade prostate intraepithelial neoplasia: a preliminary report from a one-year proof-of-principle study. Cancer Res 66: 12361240,2006

135. Ostapkowicz A, Inai K, Smith L, Kreda S and Spychala J: Lipid rafts remodeling in estrogen receptor-negative breast cancer is reversed by histone deacetylase inhibitor. Mol Cancer Ther 5: 238-245, 2006. 